\title{
Análise de crescimento de mamona semeada em diferentes épocas
}

\author{
Growth of castor sown at different times
}

\section{Rogério Ferreira Aires ${ }^{\mathrm{I}}$ Sérgio Delmar dos Anjos e Silva ${ }^{\mathrm{II}}$ Eberson Diedrich Eicholz ${ }^{\mathrm{II}}$}

RESUMO

\begin{abstract}
O objetivo deste trabalho foi estudar os efeitos dos fatores externos no crescimento, desenvolvimento e na produtividade da planta de mamona. $O$ experimento foi realizado com a cultivar 'BRS Energia' semeada em três épocas nas safras 2008/09 e 2009/10 em Pelotas - RS. As variáveis avaliadas foram a taxa de crescimento relativo (TCR), taxa assimilatória líquida $(T A L)$, produtividade e as principais variáveis meteorológicas. A maior taxa de crescimento relativo e assimilatória líquida ocorre nos períodos de temperatura média de 22,5 a $25,7^{\circ} \mathrm{C}$ e insolação média diária maior que seis horas, que coincidem com as semeaduras de novembro e dezembro na região de Pelotas, enquanto as maiores produtividades ocorrem nas semeaduras de outubro e novembro.
\end{abstract}

Palavras-chave: Ricinus communis, cultivar 'BRS Energia', taxa de crescimento relativo, taxa assimilatória líquida.

\section{ABSTRACT}

The objective was to study external effects on growth, development and plant productivity. The experiment was conducted with 'BRS Energia' sown at three times in 2008/ 09 and 2009/10 seasons in Pelotas, Southern Brazil. It was evaluated the relative growth rate (RGR), net assimilation rate $(N A R)$, yield and the main meteorological variables. The highest relative growth rate and net assimilation rate occurred at an average temperature of 22.5 to $25.7^{\circ} \mathrm{C}$ and average daily insolation greater than six hours, which coincide with November and December sowings in Southern Brazil. The highest yields were observed in October and November sowings.

Key words: Ricinus communis, 'BRS Energia', relative growth rate, net assimilation rate.

\section{INTRODUÇÃO}

A produtividade vegetal é o resultado da interação entre os fatores genéticos, ambientais e os tratos culturais, os quais constituem o sistema de produção das culturas. Dessa forma, diferenças de rendimento entre safras e locais podem ser atribuídas à interação genótipo $\mathrm{x}$ ambiente $\mathrm{x}$ manejo da cultura.

Na parte genética, o homem interfere através do desenvolvimento de cultivares com melhores características agronômicas e mais adaptadas à determinada região. Em relação ao ambiente, procurase minimizar os riscos através de práticas de manejo da cultura e do zoneamento agroclimático. Assim, tanto para o desenvolvimento de um programa de melhoramento, quanto para a indicação de práticas de manejo e elaboração do zoneamento, é necessário conhecimento profundo do efeito das condições ambientais nos processos de crescimento, desenvolvimento e produtividade da planta.

Para as espécies, há uma enorme variação em seus mecanismos de assimilação, entretanto, os controles de crescimento inerentes à planta exercem grandes efeitos sobre o seu desempenho geral. Insumos físicos sustentam o crescimento, mas a regulação biológica dita o modelo da sua utilização e a expressão final. Para entender a natureza desta regulação ao nível de planta como um todo e verificar as interações entre a planta e seu ambiente, é necessária

'Programa de Pós-graduação em Sistemas de Produção Agrícola Familiar, Universidade Federal de Pelotas (UFPel), 96010-900, Pelotas, RS, Brasil. Email: rogeriofaem@yahoo.com.br. Autor para correspondência.

"Embrapa Clima Temperado, Pelotas, RS, Brasil. 
mensuração mais detalhada do que simplesmente a produção final. Análises de crescimento e modelos matemáticos do crescimento e desenvolvimento fornecem tais parâmetros (LEOPOLD, 1975).

A mamona é uma planta de origem tropical, de metabolismo $\mathrm{C}_{3}$, elevada plasticidade fenotípica e ampla adaptação a diferentes ambientes (WEISS, 2000), entretanto, as variações ambientais influenciam no desempenho agronômico da cultura. A produtividade da mamona está diretamente relacionada com a disponibilidade hídrica, temperatura, fotoperíodo e umidade relativa do ar (MOSHKIN, 1986; KUMAR et al., 1997).

As análises de crescimento fornecem informações de todo o ciclo da planta, possibilitando relacionar características morfofisiológicas, fatores externos e produtividade, sendo que essas informações são fundamentais para definir algumas práticas de manejo, tal como a escolha da época de semeadura, e para fornecer subsídios para a escolha e desenvolvimento de cultivares para as condições climáticas da região Sul do Brasil.

Nesse sentido, o objetivo deste trabalho foi estudar o efeito das principais variáveis meteorológicas no crescimento, desenvolvimento e produtividade da mamona.

\section{MATERIAL E MÉTODOS}

O experimento foi realizado no campo experimental da Embrapa Clima Temperado em Pelotas - RS, latitude $31^{\circ} 41^{\prime} \mathrm{Sul}$, longitude 52²1' Oeste e altitude de $60 \mathrm{~m}$, em solo classificado como Argissolo Vermelho Amarelo, nas safras 2008/09 e 2009/10.

A cultivar utilizada foi a 'BRS Energia', desenvolvida em rede pela Embrapa, EBDA e Emparn e lançada em 2007. No Rio Grande do Sul, essa cultivar tem se caracterizado pelo porte médio, ciclo precoce e um grande número de racemos por planta (AIRES et al., 2010).

A semeadura foi realizada em três épocas para cada ano, 17/09/08, 20/10/08, 20/11/08, 15/10/09, 10/12/09 e 15/01/10 em espaçamento de 1,0 x 1,2m, totalizando 8.333 plantas por hectare. O cultivo foi estabelecido em sistema convencional de preparo do solo, com semeadura manual, utilizando-se três sementes por cova. O desbaste foi realizado aos 14 dias após a emergência, mantendo-se uma planta por cova; a adubação e os demais tratos culturais foram realizados de acordo com as indicações técnicas para o cultivo da mamona no Rio Grande do Sul (SILVA et al., 2007).

O delineamento experimental foi em blocos completos casualizados com três repetições e as parcelas foram compostas por seis linhas de oito metros. Para avaliação de produtividade, foi colhida uma linha, totalizando $9,6 \mathrm{~m}^{2}$ de área útil, sendo realizadas três colheitas manuais devido à maturação desuniforme dos racemos. As avaliações fenológicas e de rendimento realizadas foram: data da emergência de $50 \%$ das plantas, data do início da floração dos racemos de 1aㅡ, 2 e de $3^{\underline{a}}$ ordem, determinada pela abertura das primeiras flores femininas, produção de sementes por planta, relação entre o peso de grão e o peso do fruto seco com casca (semente/fruto) e produtividade. Paralelamente, também foi realizado o monitoramento da ocorrência de pragas e doenças, uma vez que podem causar prejuízos significativos à produtividade e devem ser considerados na escolha da época de semeadura.

A fim de comparar os tratamentos sempre no mesmo estádio fenológico, o ciclo da planta foi dividido em três estádios de fácil identificação: estádio vegetativo (VG), compreendido entre a emergência e a floração dos racemos de primeira ordem; reprodutivo 1 (R1), entre a floração dos racemos de primeira e segunda ordem e; reprodutivo 2 (R2), entre a floração dos racemos de segunda e terceira ordem.

O acompanhamento do crescimento foi realizado através de coletas para determinação da matéria seca (MS) e área foliar (AF), as quais foram realizadas a cada 14 dias, iniciando aos 14 dias após a emergência, sendo coletada uma planta por parcela, alternadamente, de forma a impedir que as plantas avaliadas fossem beneficiadas pelo espaço deixado pela coleta anterior. Para obtenção da matéria seca, as plantas foram cortadas rente ao solo e separadas em partes (folhas, caule, frutos) e a secagem foi realizada em estufa, a uma temperatura de $65^{\circ} \mathrm{C}$ até peso constante.

Para a determinação da área foliar, as folhas foram fotografadas, com câmera digital, em um fundo branco com uma linha de referência de comprimento conhecido. Posteriormente, as imagens foram transferidas para o computador para o cálculo da área foliar, com auxílio do programa Image Tool ${ }^{\circledR}$. Até os 28 dias após a emergência, todas as folhas da planta foram fotografadas e, nas coletas posteriores, foi retirada uma subamostra de no mínimo $25 \%$ do peso das folhas de cada planta colhida. A área foliar determinada foi relacionada com a matéria seca da subamostra, obtendose a área foliar específica (AFE), dada em unidade de área por unidade de matéria seca da folha $\left(\mathrm{cm}^{2} \mathrm{mg}^{-1}\right)$. Finalmente, a matéria seca total das folhas da amostra foi convertida em área foliar por meio da multiplicação pela área foliar específica (AFE).

Inicialmente, os dados primários de área foliar e matéria seca foram transformados através da 
transformação logarítmica, com o objetivo de homogeneizar a variância (HUNT, 2003; POORTER \& GARNIER, 1996). Posteriormente, calculou-se a taxa de crescimento relativo (TCR) e a taxa assimilatória líquida (TAL), de acordo com as equações e métodos descritos por HUNT (2003) e POORTER (1989).

A taxa de crescimento relativo (TCR) é o incremento de massa seca por unidade de massa existente, pode ser expressa em unidade de massa por massa ou em percentagem (HUNT, 2003), cujo cálculo é realizado dividindo-se a diferença entre a massa seca entre duas coletas pelo intervalo de tempo entre elas, como descrito na equação 1 , em que $\ln$ MS são os dados transformados de massa seca e t o tempo.

(1) $T C R=\frac{\ln M S_{\mathrm{z}}-\ln M S_{1}}{t_{\mathrm{z}}-t_{1}}$

A taxa assimilatória líquida (TAL) é um índice de eficiência fotossintética da planta, calculada em função da área foliar total (HUNT, 2003), que é expressa em massa seca por unidade de área foliar por tempo, ou seja, a quantidade de matéria seca assimilada por unidade de área foliar por dia (Equação 2).

(2) $T A L=\frac{M S_{2}-M S_{1}}{t_{\mathrm{z}}-t_{1}}-\frac{\ln A F_{\mathrm{z}}-\ln A F_{1}}{A F_{\mathrm{z}}-A F_{1}}$

Os dados meteorológicos (precipitação, temperatura do ar, umidade relativa do ar e insolação) foram obtidos junto à estação agrometeorológica da Embrapa Clima Temperado, localizada próximo da área experimental.

Foram realizadas análises de correlação entre as variáveis resposta e as variáveis meteorológicas e análise com discriminação da variância entre as semeaduras. Nas análises estatísticas, utilizou-se o software estatístico SAS (SAS INSTITUTE, 1999).

\section{RESULTADOS E DISCUSSÃO}

A taxa de crescimento relativo no período vegetativo foi maior nas semeaduras de novembro, dezembro e janeiro e, no período R1, foi maior nas semeaduras de outubro, novembroe dezembro (Tabela 1); as maiores taxas de crescimento foram observadas nos períodos de maior temperatura média do ar (Tabela 2). Na tabela 3, observa-se uma alta correlação positiva significativa da temperatura média do ar com a taxa de crescimento relativo; ao contrário, em R2, observa-se uma correlação negativa significativa da temperatura com a taxa de crescimento relativo (Tabela 3 ). Entretanto, este resultado também é um indicativo do efeito positivo da temperatura sobre o crescimento nas fases iniciais do desenvolvimento da planta, pois a taxa de crescimento relativo diminui com o crescimento e desenvolvimento da planta.

À medida que a planta cresce a proporção da sua massa alocada em estruturas de sustentação e reprodutivas, não diretamente produtivas, cresce, reduzindo o incremento de massa seca por unidade existente (HUNT, 2003). Portanto, taxas de crescimento inicialmente altas reduzem mais rapidamente do que taxas inicialmente baixas, em outras palavras, quanto maior o crescimento nas fases iniciais, menores serão as taxas de crescimento nas fases seguintes. $O$ comportamento da taxa assimilatória líquida foi semelhante ao da taxa de crescimento relativo em relação à temperatura (Tabela 3). A taxa assimilatória líquida também diminui com o crescimento da planta, devido ao sombreamento das folhas.

Tabela 1 - Taxa de crescimento relativo (TCR) e assimilatória líquida (TAL) do período vegetativo (VG), do período entre a primeira e a segunda floração (R1) e entre a segunda e a terceira floração (R2) da mamona cultivar 'BRS Energia' semeada em diferentes épocas, em Pelotas-RS.

\begin{tabular}{|c|c|c|c|c|c|c|c|c|c|c|c|c|}
\hline \multirow{3}{*}{$\begin{array}{l}\text { Semeadura } \\
17 / 09 / 08\end{array}$} & \multicolumn{6}{|c|}{ 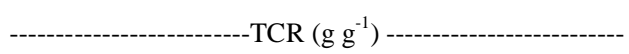 } & \multicolumn{6}{|c|}{--TAL $\left(\mathrm{mg} \mathrm{cm}^{-2} \mathrm{dia}^{-1}\right)$} \\
\hline & \multicolumn{2}{|c|}{------VG------ } & \multicolumn{2}{|c|}{------R1------ } & \multicolumn{2}{|c|}{------R2------ } & \multicolumn{2}{|c|}{------VG------ } & \multicolumn{2}{|c|}{------R1------ } & \multicolumn{2}{|c|}{------R2------ } \\
\hline & 0,068 & $\mathrm{~d}$ & 0,052 & $\mathrm{bc}$ & 0,039 & ns & 0,869 & $\mathrm{~b}$ & 0,776 & a & 0,555 & ns \\
\hline 20/10/08 & 0,091 & $\mathrm{c}$ & 0,067 & $\mathrm{ab}$ & 0,046 & & 1,032 & $a b$ & 0,752 & a & 0,613 & \\
\hline 20/11/08 & 0,113 & $\mathrm{~b}$ & 0,080 & a & 0,046 & & 1,099 & a & 0,833 & a & 0,634 & \\
\hline $15 / 10 / 09$ & 0,075 & $\mathrm{~cd}$ & 0,081 & $\mathrm{a}$ & 0,063 & & 0,572 & $\mathrm{c}$ & 0,841 & a & 0,842 & \\
\hline $10 / 12 / 09$ & 0,145 & $\mathrm{a}$ & 0,072 & $\mathrm{a}$ & 0,040 & & 1,049 & $a b$ & 0,750 & $\mathrm{a}$ & 0,600 & \\
\hline $15 / 01 / 10$ & 0,121 & $\mathrm{~b}$ & 0,034 & $\mathrm{c}$ & 0,066 & & 1,026 & $a b$ & 0,438 & $\mathrm{~b}$ & 0,919 & \\
\hline Média & 0,102 & & 0,064 & & 0,050 & & 0,941 & & 0,731 & & 0,694 & \\
\hline $\mathrm{CV}$ & 11,8 & & 15,4 & & 24,9 & & 11,4 & & 17,5 & & 24,1 & \\
\hline
\end{tabular}

Médias seguidas de mesma letra na coluna não diferem pelo teste de Duncan $(\alpha=0,05)$; "ns" indica que as médias da coluna não diferem significativamente na análise de variância.

Ciência Rural, v.41, n.8, ago, 2011. 
Tabela 2 - Precipitação acumulada (Prec), umidade relativa do ar (UR), temperatura média do ar (T), insolação acumulada (INSA) e insolação média diária (INSM), em horas e décimos do período vegetativo (VG), reprodutivo 1, entre a primeira e a segunda floração (R1) e reprodutivo 2, entre a segunda e a terceira floração (R2), da mamona cultivar 'BRS Energia' em Pelotas-RS.

\begin{tabular}{|c|c|c|c|c|c|}
\hline Semeadura & Prec (mm) & UR $(\%)$ & $\mathrm{T}\left({ }^{\circ} \mathrm{C}\right)$ & INSA & INSM \\
\hline & & & $---V G-$ & ------- & ----- \\
\hline $17 / 09 / 2008$ & 71 & 70 & 20,0 & 312,5 & 7,3 \\
\hline $20 / 10 / 2008$ & 78 & 68 & 21,1 & 312,6 & 7,8 \\
\hline $20 / 11 / 2008$ & 35 & 64 & 22,6 & 282,5 & 8,7 \\
\hline $15 / 10 / 2009$ & 491 & 73 & 21,1 & 297,9 & 4,9 \\
\hline $10 / 12 / 2009$ & 77 & 70 & 23,3 & 259,4 & 6,9 \\
\hline $15 / 01 / 2010$ & 272 & 72 & 24,0 & 268,8 & 6,3 \\
\hline $17 / 09 / 2008$ & 55 & 67 & 21,4 & 136,7 & 6,8 \\
\hline $20 / 10 / 2008$ & 16 & 64 & 22,9 & 171,8 & 9,0 \\
\hline $20 / 11 / 2008$ & 57 & 68 & 22,5 & 140,1 & 8,2 \\
\hline $15 / 10 / 2009$ & 31 & 70 & 23,3 & 99,4 & 7,1 \\
\hline $10 / 12 / 2009$ & 103 & 71 & 25,7 & 80,4 & 6,0 \\
\hline $15 / 01 / 2010$ & 45 & 70 & 21,3 & 136,2 & 6,8 \\
\hline $17 / 09 / 2008$ & 16 & 64 & 22,9 & 171,8 & 9,0 \\
\hline $20 / 10 / 2008$ & 60 & 66 & 22,6 & 170,6 & 8,1 \\
\hline $20 / 11 / 2008$ & 120 & 70 & 22,9 & 185,2 & 8,5 \\
\hline $15 / 10 / 2009$ & 12 & 67 & 22,9 & 151,9 & 9,0 \\
\hline $10 / 12 / 2009$ & 125 & 73 & 24,2 & 83,0 & 5,5 \\
\hline $15 / 01 / 2010$ & 37 & 69 & 20,0 & 97,2 & 7,5 \\
\hline
\end{tabular}

A temperatura média do ar nos períodos estudados variou entre 20 e $25,7^{\circ} \mathrm{C}$ (Tabela 2 ), sendo que, nesse intervalo, foi observada uma alta correlação positiva da temperatura com a taxa de crescimento relativo e a taxa assimilatória líquida no período vegetativo, e com a taxa de crescimento relativo em R1 (Tabela 3). Esse resultado está de acordo com WEISS (2000) e MOSHKIN (1986), que afirmam que a temperatura ótima para cultivo da mamona está entre 20 e $30^{\circ} \mathrm{C}$.

Experimentos com mamona em condições controladas demonstraram que, nas condições de alta luminosidade e baixo déficit de pressão de vapor entre a folha e a atmosfera, ou seja, umidade relativa do ar mais elevada, a maior taxa de assimilação de dióxido de carbono ocorre na faixa de temperatura entre 30 e $35^{\circ} \mathrm{C}$ (DAI et al., 1992). Entretanto, a temperatura ótima para a fotossíntese líquida se situa abaixo da temperatura ótima para a fotossíntese bruta, pois em condições de alta temperatura a fotorrespiração e a respiração mitocondrial diminuem o rendimento fotossintético (LARCHER, 2006). De acordo com AZEVEDO \& BELTRÃO (2007), a maior fotossíntese líquida ocorre aos $23^{\circ} \mathrm{C}$, porém, outros fatores externos interferem na temperatura ótima para a fotossíntese, por exemplo, em condições de fraca radiação (LARCHER, 2006) ou de baixa umidade relativa do ar (DAI et al., 1992), a temperatura ótima é deslocada para baixo.
A umidade relativa tem grande influência no crescimento da mamona e, quando menor que $30 \%$, ocorre redução da taxa fotossintética (MOSHKIN, 1986). De acordo com DAI et al. (1992), a fotossíntese em mamona é muito sensível a mudanças na umidade relativa, sendo que a principal causa do efeito inibitório da baixa umidade relativa sobre a fotossíntese se deve, principalmente, ao fechamento estomático. Para AZEVEDO \& BELTRÃO (2007), a faixa de umidade relativa ideal para a mamona vai de 50 a $65 \%$. Neste trabalho, a amplitude de variação da umidade relativa do ar foi de 64 a $73 \%$ (Tabela 2), sendo que a maior produtividade foi obtida nas épocas em que a umidade relativa foi menor, principalmente na fase reprodutiva. Pelos dados da tabela 3, observou-se alta correlação negativa da umidade relativa e temperatura em R1 com a produção de sementes por planta. A combinação de alta umidade relativa com temperatura em torno de $25^{\circ} \mathrm{C}$ é ideal para o desenvolvimento do fungo Amphobotrys ricini, que ataca os racemos, principalmente na floração, causando grandes prejuízos à produtividade.

Na safra 2009/10, o excesso de chuvas resultou em uma condição de alta umidade relativa e baixa insolação, reduzindo a taxa assimilatória líquida do período vegetativo. $\mathrm{Na}$ tabela 3 , observa-se que a taxa assimilatória líquida se correlacionou negativamente com a umidade relativa e a precipitação 
Tabela 3 - Coeficiente de correlação de Pearson e a respectiva significância das variáveis: tempo entre a emergência e o final do período (F), matéria seca da planta ao final do período (MSF), área foliar da planta ao final do período (AFF), Taxa de crescimento relativo (TCR) e Taxa assimilatória líquida (TAL), relação semente/fruto (S/F), produção de grãos por planta (PP) e produtividade (Prod), com as variáveis: precipitação (Prec), umidade relativa do ar (UR), temperatura (T) e insolação média diária (INSM) na mamona cultivar 'BRS Energia', em Pelotas-RS.

\begin{tabular}{|c|c|c|c|c|c|c|c|c|}
\hline & $\mathrm{F}$ & MSF & $\mathrm{AFF}$ & TCR & TAL & $\mathrm{S} / \mathrm{F}$ & PP & Prod \\
\hline \multirow[t]{2}{*}{ Prec } & 0,892 & 0,118 & 0,114 & $-0,282$ & $-0,720$ & 0,271 & $-0,456$ & $-0,126$ \\
\hline & $<0,0001$ & 0,6421 & 0,6537 & 0,2568 & 0,0008 & 0,3278 & 0,0874 & 0,6535 \\
\hline \multirow[t]{2}{*}{ UR } & 0,780 & 0,247 & 0,208 & $-0,224$ & $-0,617$ & 0,157 & $-0,494$ & $-0,568$ \\
\hline & 0,0001 & 0,3239 & 0,4066 & 0,3709 & 0,0063 & 0,5768 & 0,0615 & 0,0272 \\
\hline \multirow[t]{2}{*}{$\mathrm{T}$} & $-0,382$ & 0,750 & 0,748 & 0,855 & 0,488 & 0,033 & $-0,418$ & 0,162 \\
\hline & 0,1177 & 0,0003 & 0,0004 & $<0,0001$ & 0,0400 & 0,9075 & 0,1212 & 0,5648 \\
\hline \multirow[t]{2}{*}{ INSM } & $-0,864$ & $-0,195$ & $-0,211$ & 0,183 & 0,700 & $-0,210$ & 0,598 & 0,404 \\
\hline & $<0,0001$ & 0,4386 & 0,4017 & 0,4676 & 0,0012 & 0,4529 & 0,0184 & 0,1354 \\
\hline \multirow[t]{2}{*}{ Prec } & $-0,489$ & 0,340 & 0,270 & 0,090 & 0,082 & 0,079 & $-0,405$ & $-0,427$ \\
\hline & 0,0394 & 0,1671 & 0,2783 & 0,7216 & 0,7475 & 0,7799 & 0,1342 & 0,1124 \\
\hline \multirow[t]{2}{*}{ UR } & 0,054 & 0,243 & 0,214 & 0,069 & $-0,108$ & 0,134 & $-0,731$ & $-0,387$ \\
\hline & 0,8312 & 0,3322 & 0,3946 & 0,7846 & 0,6691 & 0,6338 & 0,0020 & 0,1539 \\
\hline \multirow[t]{2}{*}{$\mathrm{T}$} & $-0,289$ & 0,539 & 0,633 & 0,511 & 0,272 & 0,174 & $-0,684$ & $-0,100$ \\
\hline & 0,2440 & 0,0209 & 0,0048 & 0,0301 & 0,2759 & 0,5344 & 0,0050 & 0,7240 \\
\hline \multirow[t]{2}{*}{ INSM } & $-0,160$ & $-0,129$ & 0,001 & 0,245 & 0,198 & $-0,179$ & 0,549 & 0,692 \\
\hline & 0,5258 & 0,6109 & 0,9958 & 0,3265 & 0,4316 & 0,5241 & 0,0339 & 0,0043 \\
\hline \multirow[t]{2}{*}{ Prec } & $-0,869$ & 0,274 & 0,118 & $-0,280$ & $-0,259$ & $-0,120$ & $-0,140$ & 0,247 \\
\hline & $<0,0001$ & 0,2718 & 0,6414 & 0,2601 & 0,3003 & 0,6694 & 0,6191 & 0,3741 \\
\hline \multirow[t]{2}{*}{ UR } & $-0,799$ & 0,381 & 0,200 & $-0,049$ & 0,010 & $-0,013$ & $-0,452$ & 0,084 \\
\hline & $<0,0001$ & 0,1188 & 0,4265 & 0,8458 & 0,9673 & 0,9646 & 0,0904 & 0,7671 \\
\hline \multirow[t]{2}{*}{$\mathrm{T}$} & $-0,116$ & $-0,319$ & $-0,461$ & $-0,517$ & $-0,506$ & $-0,088$ & $-0,659$ & $-0,447$ \\
\hline & 0,6463 & 0,1967 & 0,0540 & 0,0279 & 0,0321 & 0,7563 & 0,0076 & 0,0950 \\
\hline \multirow[t]{2}{*}{ INSM } & 0,735 & $-0,325$ & $-0,191$ & 0,143 & 0,069 & $-0,018$ & 0,509 & 0,203 \\
\hline & 0,0005 & 0,1883 & 0,4468 & 0,5713 & 0,7846 & 0,9496 & 0,0525 & 0,469 \\
\hline
\end{tabular}

e, positivamente, com a temperatura e insolação médias no período vegetativo. Entretanto, esse resultado não pode ser entendido como efeito negativo da umidade relativa sobre a fotossíntese, pois, provavelmente, a forte redução da taxa assimilatória líquida nos períodos de alta umidade se deve mais à redução da insolação pelo tempo chuvoso e encoberto.

O ciclo da planta variou em função da época de semeadura, de forma que em novembro de 2008 observou-se o menor período vegetativo, enquanto que o maior foi observado na semeadura de outubro de 2009 (Tabela 4). As condições meteorológicas dessas semeaduras foram bem distintas, pois, na de novembro de 2008, houve maior insolação média diária e temperatura no estádio vegetativo que na semeadura de outubro de 2009, caracterizada pelo excesso de chuvas e tempo encoberto, resultando na menor insolação dentre todas as épocas (Tabela 2).

Para a duração do período vegetativo, constatou-se alta correlação positiva com a precipitação e a umidade relativa do ar e alta correlação negativa com a insolação média diária (Tabela 3), ou seja, em condições meteorológicas desfavoráveis, o período vegetativo é maior, enquanto que em condições mais favoráveis as florações são antecipadas, diminuindo o ciclo da planta.

A condição desfavorável, de tempo chuvoso e encoberto, da safra 2009/10 favoreceu o ataque de Amphobotrys ricini, reduzindo severamente a produtividade e até, no caso da semeadura de janeiro, inviabilizando a produção (Tabela 4). O controle desse fungo na mamona é praticamente inviável, pois não existem fungicidas registrados e o porte da planta dificulta a aplicação.

As maiores produtividades ocorreram nas semeaduras de outubro e novembro/2008 (Tabela 4), cujo resultado concorda com outros autores que analisaram a época de semeadura da mamoneira no Rio Grande do Sul (EICHOLZ et al., 2010; SILVAet al., 2010; AIRES et al., 2008; SILVA et al., 2008), porque, embora 
Tabela 4 - Floração dos racemos de primeira (F1), segunda (F2) e terceira ordem (F3) em dias após a emergência (DAE), relação semente/fruto (S/F) e produtividade da mamona cultivar 'BRS Energia' semeada em diferentes épocas, em Pelotas-RS.

\begin{tabular}{|c|c|c|c|c|c|c|c|c|c|c|}
\hline \multirow{2}{*}{$\begin{array}{l}\text { Semeadura } \\
17 / 09 / 08\end{array}$} & \multicolumn{6}{|c|}{ 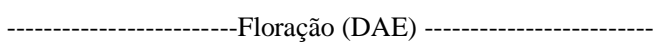 } & \multicolumn{2}{|c|}{--------S/F--------- } & \multicolumn{2}{|c|}{ Produtividade $\left(\mathrm{kg} \mathrm{ha}^{-1}\right)$} \\
\hline & 43 & $\mathrm{~b}$ & 63 & $\mathrm{~b}$ & 82 & $\mathrm{~b}$ & 0,61 & $\mathrm{~ns}$ & 546 & $\mathrm{~b}$ \\
\hline 20/10/08 & 39 & $\mathrm{bc}$ & 57 & $\mathrm{c}$ & 76 & $\mathrm{c}$ & 0,63 & & 1.773 & a \\
\hline 20/11/08 & 32 & d & 48 & $\mathrm{~d}$ & 69 & $\mathrm{~d}$ & 0,63 & & 1.834 & a \\
\hline $15 / 10 / 09$ & 60 & a & 73 & a & 89 & $\mathrm{a}$ & 0,68 & & 1.073 & $\mathrm{~b}$ \\
\hline $10 / 12 / 09$ & 36 & $\mathrm{~cd}$ & 50 & d & 64 & $\mathrm{e}$ & 0,63 & & 706 & $\mathrm{~b}$ \\
\hline $15 / 01 / 10$ & 42 & $\mathrm{~b}$ & 61 & $\mathrm{~b}$ & 73 & $\mathrm{~cd}$ & - & & - & \\
\hline Média & 42 & & 59 & & 76 & & 0,63 & & 1.186 & \\
\hline CV & 5,7 & & 2,5 & & 3,1 & & 14,8 & & 27,8 & \\
\hline
\end{tabular}

Médias seguidas de mesma letra na coluna não diferem pelo teste de Duncan $(\alpha=0,05)$; "ns" indica que as médias da coluna não diferem significativamente na análise de variância.

nas semeaduras de outubro ocorram taxas de crescimento menores no período vegetativo, o período reprodutivo ocorre em condições mais favoráveis, nos meses de novembro, dezembro e janeiro, permitindo um melhor rendimento.

O principal fator limitante à antecipação da semeadura para o mês de setembro ou o início de outubro é a baixa temperatura, que prejudica a emergência das plântulas e diminui o estande da lavoura. Nas semeaduras mais tardias, em dezembro e janeiro, parte do período reprodutivo ocorre fora do período ideal. Além de prejudicar a fotossíntese, a redução da temperatura média a partir de fevereiro aumenta o risco de ocorrência de doenças. Esse problema é mais grave nas cultivares de ciclo longo, em que a produtividade da segunda e da terceira ordem de racemos é bastante prejudicada na semeadura tardia (SILVA et al., 2008).

\section{CONCLUSÃO}

As maiores taxas de crescimento relativo no período vegetativo e no reprodutivo 1 , para a mamona cultivar BRS Energia na região de Pelotas, ocorrem em condições de temperatura média de 22,5 a $25,7^{\circ} \mathrm{C}$ e insolação média diária maior que seis horas.

\section{REFERÊNCIAS}

AIRES, R.F. et al. Ensaio de variedades de mamona no Rio Grande do Sul nas safras 2008/09 e 2009/10. In: SIMPÓSIO ESTADUAL DE AGROENERGIA, 3.; REUNIÃO TÉCNICA ANUAL DE AGROENERGIA, 3.; REUNIÃO TÉCNICA DA MANDIOCA, 10.; REUNIÃO TÉCNICA DA BATATA-DOCE, 2., 2010, Pelotas, RS. Anais... Pelotas: Embrapa Clima Temperado, 2010. $1 \mathrm{CD}$.

AIRES, R.F. et al. Épocas de semeadura de mamona conduzida por duas safras em Pelotas-RS. In: CONGRESSO BRASILEIRO DE MAMONA, 3., 2008, Salvador, Ba. Energia e ricinoquímica: anais. Salvador: SEAGRI/Embrapa Algodão, 2008. 1 CD.

AZEVEDO, D.M.P.; BELTRÃO, N.E M. O agronegócio da mamona no Brasil. Campina Grande: Embrapa Algodão, 2007. 504p.

DAI, Z. et al. Control of photosynthesis and stomatal conductance in Ricinus communis L. (Castor bean) by leaf to air vapor pressure deficit. Plant Physiology, Bethesda, v.99, n.4, p.1426-1434, 1992. Disponível em: <http:// www.plantphysiol.org/content/99/4/1426.short>. Acesso em: 30 maio, 2011. doi: 10.1104/pp.99.4.1426.

EICHOLZ, E.D. et al. Épocas de semeadura para produção de mamona em Veranópolis. In: SIMPÓSIO ESTADUAL DE AGROENERGIA, 3.; REUNIÃO TÉCNICA ANUAL DE AGROENERGIA, 3.; REUNIÃO TÉCNICA DA MANDIOCA, 10.; REUNIÃO TÉCNICA DA BATATA-DOCE, 2., Pelotas, 2010. Anais... Pelotas: Embrapa Clima Temperado, 2010. 1 CD.

HUNT, R. Growth analysis, individual plants. In: THOMAS, B. et al. (Ed.). Encyclopedia of applied plant sciences. London: Academic, 2003. p.579-588.

KUMAR, P.V. et al. Influence of moisture, thermal and photoperiodic regimes on the productivity of castor beans (Ricinus communis L.). Agricultural and forest meteorology, Amsterdam, v.88, n.4, p.279-289, 1997. Disponível em: <http:/ /www.sciencedirect.com/science/article/pii/ S0168192397000191>. Acesso em: 30 maio, 2011. doi: 10.1016/S0168-1923(97)00019-1.

LARCHER, W. Ecofisiologia vegetal. São Carlos: Rima, 2006. 550p

LEOPOLD, A.C.; KRIEDEMANN, P.E. Plant growth and development. New York: McGraw-Hill, 1975. 587p.

MOSHKIN, V.A. Castor. Moskow: Kolos Publisher, 1986. $315 \mathrm{p}$.

POORTER, H. Plant growth analysis: towards a synthesis of the classical and the functional approach. Physiologia Plantarum, Copenhagen, v.75, n.2, p.237-244, 1989. Disponível em: <http:/ /www.science.poorter.eu/1989_Poorter_PhysiolPlant.pdf > . Acesso em: 30 maio, 2011. doi: 10.1111/j.13993054.1989.tb06175.x. 
POORTER, H.; GARNIER, E. Plant growth analysis: an evaluation of experimental design and computational methods. Journal of Experimental Botany, London, v.47, n.9, p.13431351, 1996. Disponível em: <http://jxb.oxfordjournals.org/ content/47/9/1343.full.pdf+html>. Acesso em: 30 maio, 2011. doi: $10.1093 / \mathrm{jxb} / 47.9 .1343$.

SAS INSTITUTE. SAS/STAT software: changes and enhancements through release 8.02. Cary, 1999. 3 CD.

SILVA, S.D.A. et al. (Ed.). A cultura da mamona no Rio Grande do Sul. Pelotas: Embrapa Clima Temperado, 2007. 115p. (Sistemas de Produção, 11).
SILVA, S.D.A. et al. Épocas de semeadura de mamona na serra gaúcha na safra 2008/09. In: SIMPÓSIO ESTADUAL DE AGROENERGIA, 3.; REUNIÃO TÉCNICA ANUAL DE AGROENERGIA, 3.; REUNIÃO TÉCNICA DA MANDIOCA, 10.; REUNIÃO TÉCNICA DA BATATA-DOCE, 2., 2010, Pelotas, RS. Anais... Pelotas: Embrapa Clima Temperado, 2010. 1 CD.

SILVA, S.D.A. et al. Épocas de semeadura de mamona no Rio Grande do Sul. Pelotas: Embrapa Clima Temperado, 2008. 20p. (Boletim de pesquisa e desenvolvimento, 76).

WEISS, E.A. Oilseed crops. 2.ed. Oxford: Blackwell Science, 2000. 364p. 